\title{
Successful Treatment of an Early Barrett's Adenocarcinoma in a High-Risk Patient with Portal Hypertension: The "Band and Leave" Strategy
}

\author{
Miguel Fraile-López ${ }^{1,2,3}$ Jacobo Ortiz-Fernández-Sordo ${ }^{3}$ Martin James ${ }^{3}$ Philip Kaye ${ }^{3}$ Krish Ragunath ${ }^{3}$
}

${ }^{1}$ Department of Gastroenterology, Hospital Universitario Central de Asturias, Oviedo, Spain

2 Instituto de Investigación Sanitaria del Principado de Asturias (ISPA),

Address for correspondence Miguel Fraile López, MD, Endoscopy Unit, Hospital Universitario Central de Asturias, Avenida de Roma, sn Principado de Asturias, Oviedo, Spain

${ }^{3}$ NIHR Nottingham Biomedical Research Centre, Nottingham University Hospitals NHS Trust and University of Nottingham, Nottingham, United Kingdom

J Digest Endosc 2022;13:53-54.

\author{
Abstract \\ Keywords \\ - Barrett's esophagus \\ - adenocarcinoma \\ - esophageal varices \\ - endoscopic \\ procedures
}

"Band and leave" strategy has been described for the resection of submucosal tumors of the digestive tract to reduce the complications related to deep submucosal resection such as bleeding and perforation. We present the case of a patient with multiple comorbidities, chronic liver disease, and portal hypertension diagnosed to have T1 adenocarcinoma in Barrett's esophagus overlying a column of varix. This was successfully treated by band ligation and allowing the neoplastic mucosa to slough. We propose this technique as an alternative therapeutic option for the management of early Barrett's neoplasia in such high-risk patients with portal hypertension.

\section{Case Report}

A 67-year-old male with a recent diagnosis of a biopsy proven moderately differentiated early adenocarcinoma arising from a short Barrett's segment (Prague classification C0M1) was referred to our unit for endoscopic resection. He had history of stroke and compensated nonalcoholic steatohepatitis cirrhosis, Child-Pugh A (5 points), and Model for End-Stage Liver Disease score of 12 points. A computed tomography scan and endoscopic ultrasound was previously performed to exclude loco-regional and distant metastasis. Endoscopy revealed esophageal varices and a $5 \mathrm{~mm}$ flat lesion (Paris Classification 0-IIb) located close to the gastroesophageal junction at $35 \mathrm{~cm}$ from incisors, 5 o'clock position over a variceal column ( - Fig. 1). The case was discussed with the hepatology team and in the upper gastrointestinal cancer multidisciplinary meeting. Options including transinternal jugular portosystemic shunt stent to reduce portal pressure and perform endoscopic resection were considered. However, in view of the urgency to treat the cancer and the lesion being small, it was decided to adopt the "band and leave" strategy. The lesion was marked using an Argon Plasma Coagulation catheter and a single band (6 Shooter Saeed Multi-Band Ligator, Cook Medical, Ireland) was applied to the target lesion. The remaining esophageal varices were also treated in the same session with a total of five bands. After 6 months, endoscopy surveillance showed small varices and a scar with biopsies free of malignancy (-Fig. 1). At the time
DOI https://doi.org/ 10.1055/s-0040-1721224. ISSN 0976-5042. (c) 2022. Society of Gastrointestinal Endoscopy of India. All rights reserved.

This is an open access article published by Thieme under the terms of the Creative Commons Attribution-NonDerivative-NonCommercial-License, permitting copying and reproduction so long as the original work is given appropriate credit. Contents may not be used for commercial purposes, or adapted, remixed, transformed or built upon. (https://creativecommons.org/ licenses/by-nc-nd/4.0/)

Thieme Medical and Scientific Publishers Pvt. Ltd., A-12, 2nd Floor, Sector 2, Noida-201301 UP, India 
Successful Treatment of an Early Barrett's Adenocarcinoma in a High-Risk Patient with Portal Hypertension Fraile54 López et al.
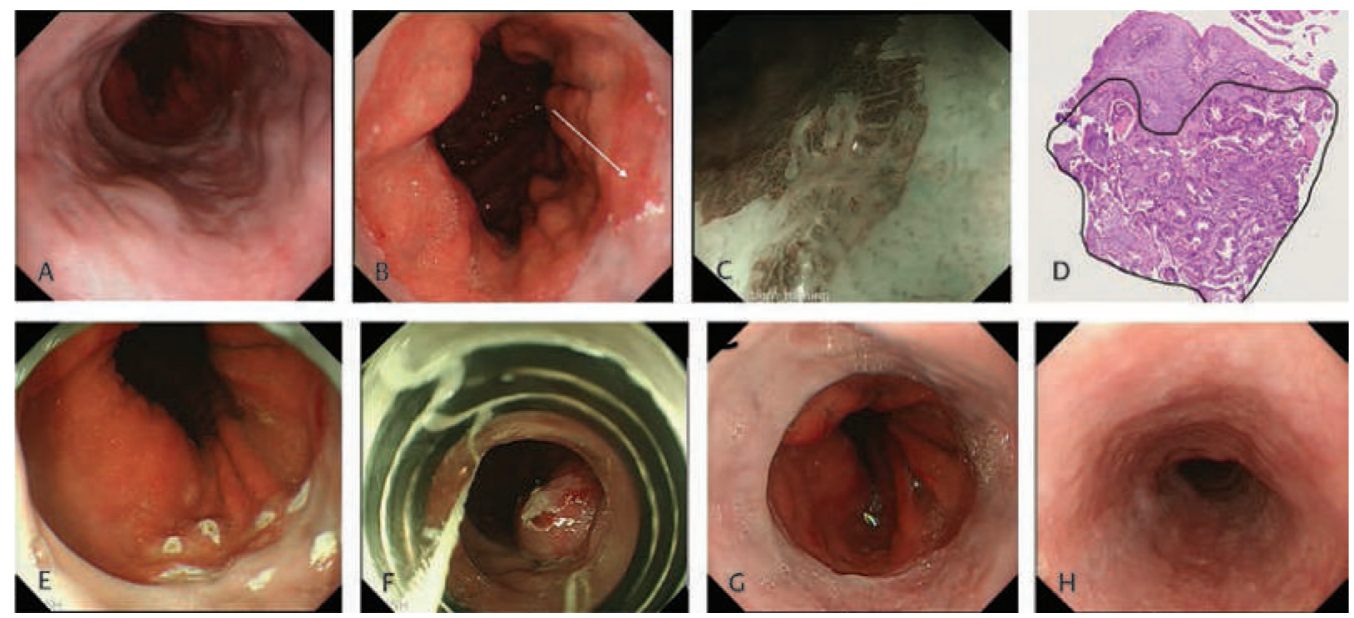

Fig. 1 (A) Esophagus varices. (B) Short Barret's tongue 5 o'clock position with an area suspicious of malignancy (white arrow). (C) Narrow band imaging magnification view of target lesion. (D) Histology of suspicious lesion showing highly atypical glandular structures compatible with adenocarcinoma (hematoxylin eosin stain) (black circle). Therapeutic approach: (E) Marked lesion with argon plasma catheter; (F) band applied.

of this report 2 years after the treatment, the patient is still alive and recurrence free.

Endoscopic band ligation is the preferred endoscopic technique for endoscopic treatment of acute esophageal variceal bleeding and secondary prophylaxis. "Band and leave" strategy has been described for endoscopic treatment of small submucosal tumors, avoiding resection and thus the risks of perforation and bleeding associated with the conventional endoscopic resection techniques. ${ }^{1-3}$ Salord et al also described a case report using this technique for the removal of a T1 esophageal squamous tumor. ${ }^{4}$ The tight rubber band causes ischemic necrosis followed by spontaneous sloughing and re-epithelization. Size of the tumor and esophageal fibrosis from previous banding can represent a limitation for this technique since it may not achieve complete ischemia of the target lesion and subsequent relapse or difficulty in including the entire lesion within the band. To our knowledge, this is the first case report of a successful treatment of an early esophageal adenocarcinoma in a patient with underlying esophageal varices. We propose this technique as an alternative therapeutic option for the management of early Barrett's neoplasia in such high-risk patients with portal hypertension.

\section{Authors Contribution}

All authors participated in the conception and design of the work.

\section{Conflict of Interest}

None declared.

\section{Acknowledgment}

To the patient, who kindly gave us permission for publication.

\section{References}

1 Ibáñez-Sanz G, Gornals JB, Rivas Let al.Endoscopic band ligation without resection in selected patients for small and superficial upper gastrointestinal tract lesions. Rev Esp Enferm Dig 2016;108 (05):250-256

2 Sun S, Jin Y, Chang G, Wang C, Li X, Wang Z. Endoscopic band ligation without electrosurgery: a new technique for excision of small upper-GI leiomyoma. Gastrointest Endosc 2004;60(02):218-222

3 Scherer JR, Holinga J, Sanders Met al.Small duodenal carcinoids: a case series comparing endoscopic resection and autoamputation with band ligation. J Clin Gastroenterol 2015;49(04):289-292

4 Salord S, Gornals J, Galan M, Botargues JM, Castellví JM, Miró M Band ligation of a T1 esophageal squamous cell cancer in a patient with multimorbidities. Endoscopy 2012;44(Suppl 2 UCTN)E171-E172 